\title{
Smooth pursuit eye movement deficits after pontine nuclei lesions in humans
}

\author{
B Gaymard, C Pierrot-Deseilligny, S Rivaud, S Velut
}

\begin{abstract}
Eye movements were recorded electrooculographically in four patients with basal pontine lesions, demonstrated by MRI. The most prominent eye movement abnormality observed was mild to severe impairment of smooth pursuit and optokinetic nystagmus, mainly ipsilateral to the lesion. This abnormality is thought to result from damage to the pontine nuclei, which form a crucial relay between the cerebral cortex and the cerebellum controlling smooth pursuit. Abnormalities of saccades and the vestibulo-ocular reflex in one patient are also discussed.
\end{abstract}

$(\Im$ Neurol Neurosurg Psychiatry 1993;56:799-807)

The pontine nuclei (PN) consist of several groups of neurons in the basis pontis relaying signals from the cerebral cortex towards the cerebellum. Some of them, namely the dorsolateral, the lateral, and the dorsomedian PN, could be specifically involved in smooth pursuit eye movements, and represent a crucial link in the corticopontine pathways mediating this eye movement. ${ }^{123}$ However, the location and function of the PN involved in smooth pursuit still have to be precisely determined in humans. The first human case with a selective $\mathrm{PN}$ lesion and including eye movement recordings was recently reported. ${ }^{4}$ It provided data consistent with the results of experimental lesion studies involving the dorsolateral pontine nuclei (DLPN) in the monkey. We report four patients with diverse vascular lesions affecting the basis pontis, resulting in various impairments of smooth pursuit and optokinetic nystagmus (OKN). The relation between smooth pursuit impairment and the location of the lesions is discussed.

Clinique Neurologique and Unité INSERM 289, Hôpital de la Salpêtrière, Paris, and Service de

Neurochirurgie, Hôpital Bretonneau, Tours, France

B Gaymard C Pierrot-Deseilligny

$S$ Rivaud

$S$ Velut

Correspondence to:

B Gaymard, INSERM 289, Hôpital de la Salpêtrière, 4 Bd de l'Hôpital, 75651 Paris, Cédex 13, France

Received 30 March 1992 and in revised from and in revised from

Accepted 25 September 1992

\section{Case reports}

PATIENT 1

A 73 year old woman had been complaining for a year and a half of a right trigeminal neuralgia despite carbamazepine therapy. She thus agreed to a neurosurgical procedure, and a microvascular decompression of the fifth nerve was performed. After surgery, the patient awoke with left hemiplegia. There was no cerebellar symptoms, no sensory loss, and no diplopia. MRI showed a right pontine lesion, compatible with a haematoma (fig 1).
This lesion was located along the lateral edge of the basis pontis, and affected about two thirds of the rostrocaudal extent of the pons (fig 2). When eye movement recordings were made, one week after surgery, the left hemiplegia had not improved, though the patient was alert and cooperative.

\section{PATIENT 2}

A 59 year old woman was hospitalised after the sudden onset of right hemiplegia. On initial examination, severe right hemiplegia was observed. On the left side, strength was normal but there was dysmetria in the finger to nose test. All sensory examination was normal. MRI showed a left pontine lesion, compatible with an infarct (fig 3). A transverse section showed that the lesion affected almost all the left basis pontis, and slightly crossed the midline (fig 3A). The pontine tegmentum was spared, except for a limited part of the median structures, on which a very narrow posterior extent of the lesion impinged (fig 2). Sagittal sections clearly showed that the lesion had a short rostrocaudal extent, and consisted of a thin horizontal slice (about $5 \mathrm{~mm}$ ) at the mid-pons level (fig 3B). MRI did not show any lesions in the superior or inferior cerebellar peduncles or in the cerebellum. Eye movement recordings were performed five months after the stroke. At that time, the motor deficit and the cerebellar syndrome persisted. The patient was alert and cooperative.

\section{PATIENT 3}

A 34 year old woman with no medical background was hospitalised after the sudden onset of pure left hemiparesis. MRI showed a lesion restricted to the basis pontis, compatible with an infarct. It was located just below the mid-pons level, along the midline, with a limited extent on the right side (fig 2). On sagittal sections, it occupied approximately $30 \%$ of the whole rostrocaudal extent of the pons. Eye movement recordings were performed one month after the stroke. At that time, there was no improvement in the motor deficit, though the patient was alert and cooperative.

\section{PATIENT 4}

A 66 year old woman with a long history of hypertension suddenly experienced isolated left hemiplegia. MRI showed a lesion compatible with an infarct, located on the right side of the brainstem, at the mid-pons level. The lesion was restricted to the basis pontis, 

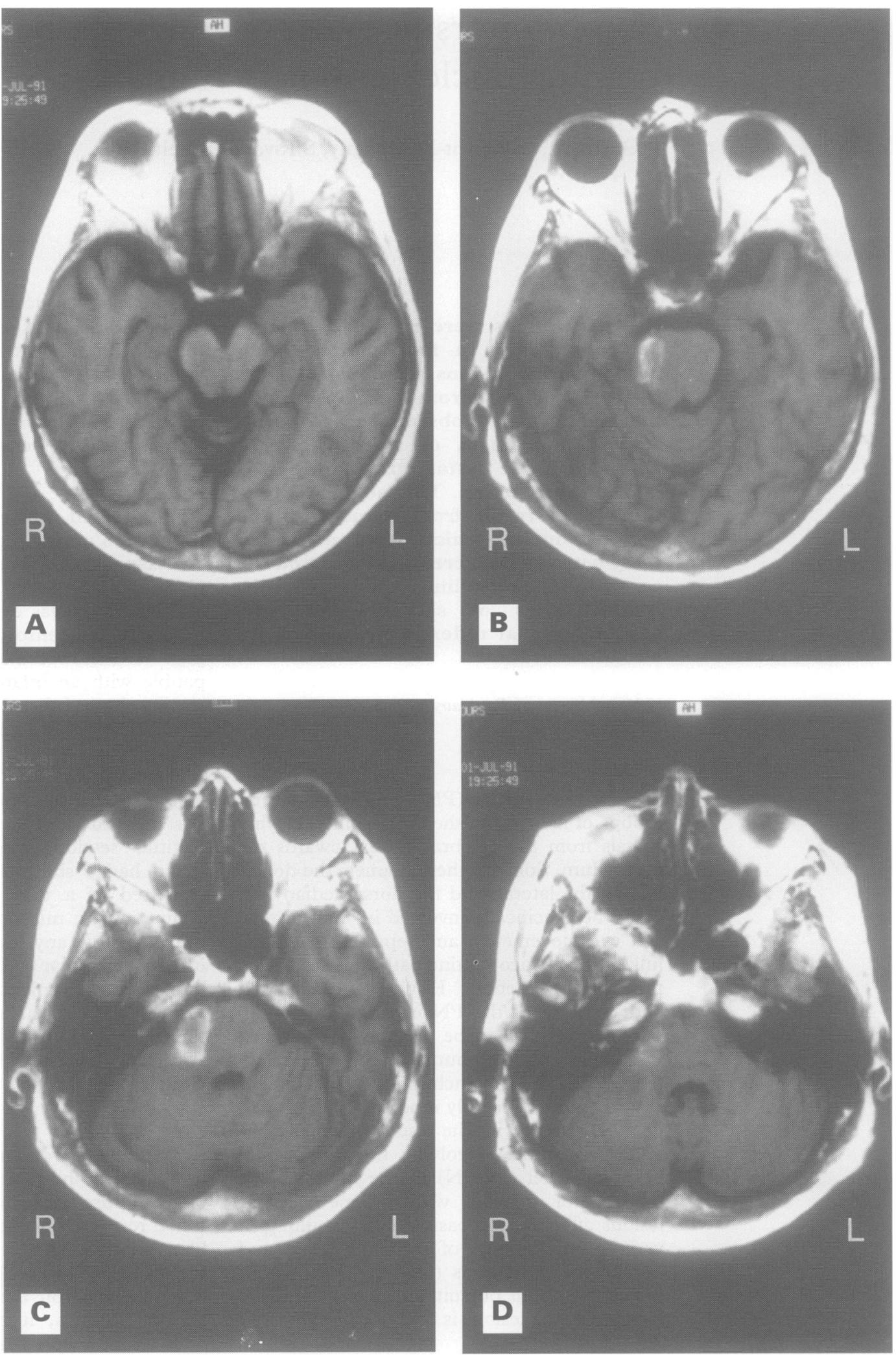

Figure $1 M R I$ of patient $1\left(T_{1}\right.$ weighted, $\left.T R=500 \mathrm{~ms}, T E=10 \mathrm{~ms}\right)$ shows a right pontine lesion, compatible with a haematoma, located in the lateral part of the basis pontis, with a marked rostrocaudal extent. $(A)$ pontomesencephalic junction, (B) upper pons, (C) mid-pons, (D) lower pons.

except on the midline where it extended slightly into the tegmentum (fig 2). On sagittal sections of the brainstem, it occupied approximately $40 \%$ of the rostrocaudal extent of the pons. Eye movements were recorded six weeks after the stroke. By this time, the motor deficit had improved moderately, and the patient was alert and cooperative.

\section{Eye movements}

For all patients, eye movements were recorded using direct current electro-oculography (EOG), with the head immobilised. Two temporal electrodes were used for horizontal eye movements, and two others were located above and below the right eye for vertical eye movements. 


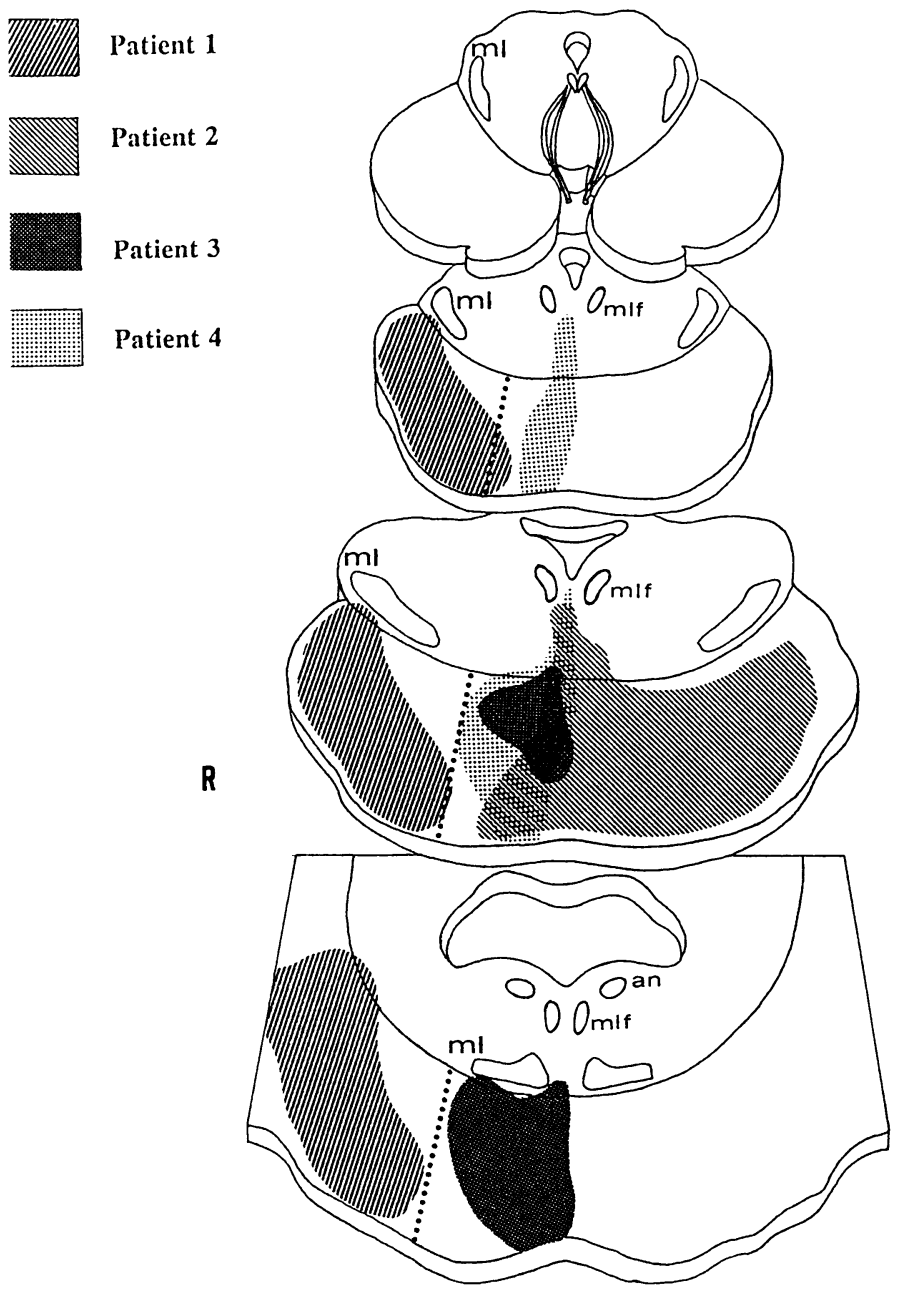

Figure 2 Drawing of the lesions of the four patients based on MRI scans (drawn by the authors). (A) midbrain, (B) upper pons, (C) mid-pons, (D) lower pons, an = abducens nucleus, $m l=$ medial lemniscus, $m l f=$ medial longitudinal fasciculus, $R=$ right. The dorsoventral broken line passes through the peduncular PN and clearly separates the $D M P N$, laterally, and the DMPN, medially.

Saccades and smooth pursuit were elicited in a dimmed room with a ramp of light emitting diodes (LED), located $80 \mathrm{~cm}$ in front of the subject. Horizontal visually guided saccades were studied by asking the subject to look as fast as possible at a suddenly appearing $20^{\circ}$ lateral target. Horizontal smooth pursuit was induced by asking the subject to track an LED moving sinusoidally with an amplitude of $\pm 20^{\circ}$, at various speeds (peak velocities of $22 \cdot 5,29$, and $45 \%$ for patient 1 , and $14.5,22.5,29$, and $45 \%$ sor the other patients). For each speed, smooth pursuit gain (defined as the ratio of peak eye velocity to peak stimulus velocity), was calculated for each lateral direction by averaging the gain obtained in 10 successive cycles. The calculation of smooth pursuit gain was made from the chart (speed of the chart paper $10 \mathrm{~mm} / \mathrm{s}$ ). Furthermore, an index of asymmetry of smooth pursuit was defined as:

$$
\frac{\text { right gain }- \text { left gain }}{\text { right gain }+ \text { left gain }} \times 100
$$

Vertical saccades and smooth pursuit were recorded under the same conditions as for horizontal eye movements, but only qualitatively analysed.
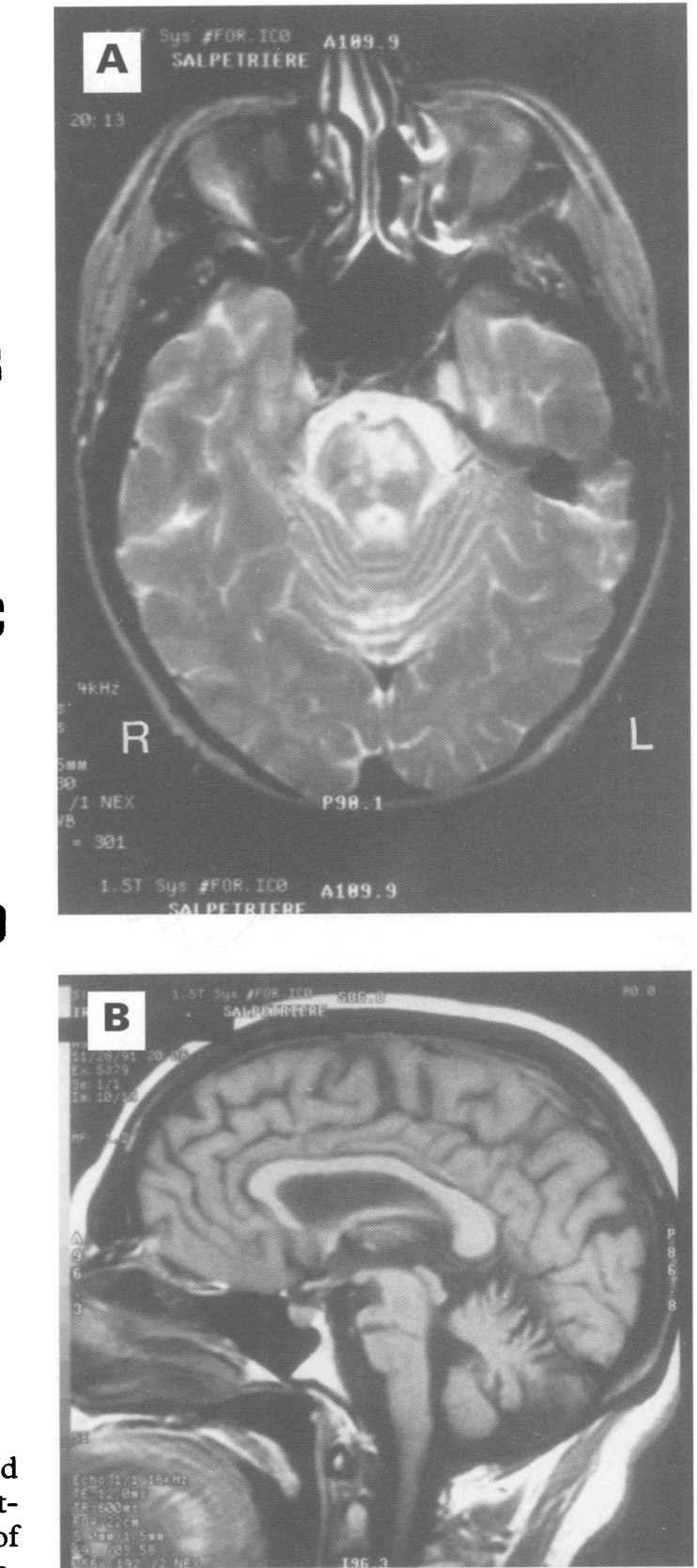

Figure 3 MRI of patient $2(T$, weighted, TR $=600 \mathrm{~ms}$, $T E=12 \mathrm{~ms}$ ) shows a left pontine lesion, compatible with an infarct. (A) horizontal section at the mid-pons level. The lesion involved almost all of the left basis pontis, with slight extension, medially into the tegmentum and contralaterally. (B) sagittal section. The lesion had a limited rostrocaudal extent.

For patient 1, horizontal OKN was obtained by the manual displacement of alternate black and white stripes over a large part of the visual field. The horizontal vestibuloocular reflex (VOR) was studied in a dimmed room on an armchair rotating with an amplitude of $\pm 20^{\circ}$, without stimulation being recorded, and VOR suppression was tested by asking the patient to fixate a target rotating with the armchair. These different eye movements were analysed qualitatively.

For the other patients, OKN was elicited by vertical black and white stripes, covering $50^{\circ}$ of the visual field and moving regularly at 10,20 , and $30 \%$ s. The horizontal VOR was studied in complete darkness, using a chair 

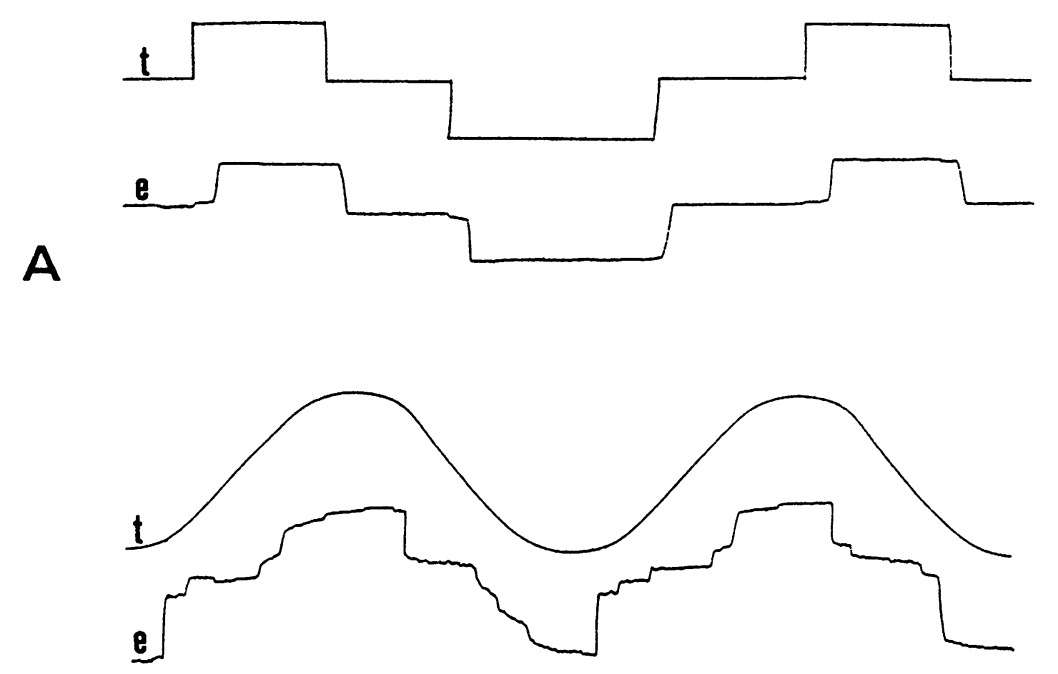

B
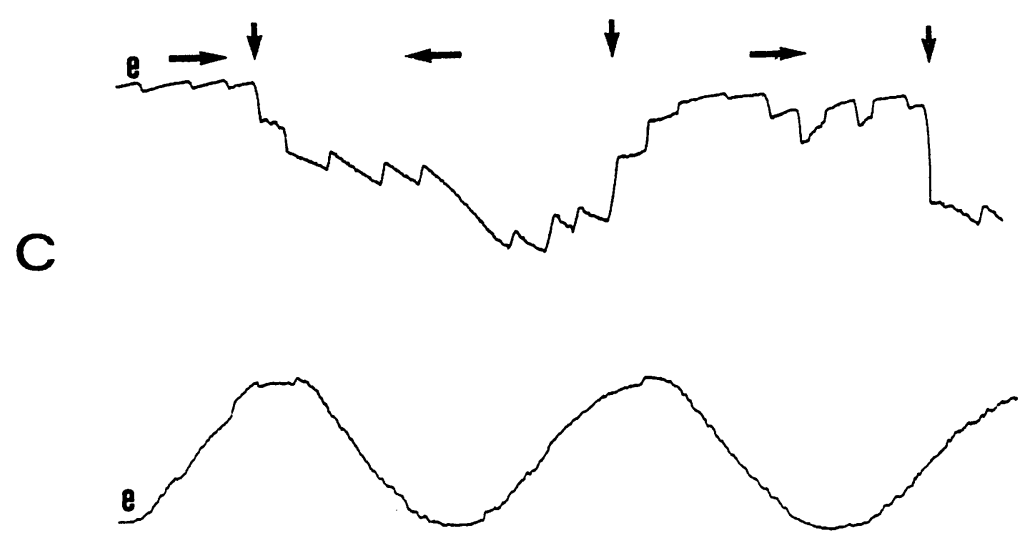

D

$\stackrel{e}{e}$

$\mathbf{E}$

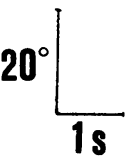

Figure 4 Horizontal eye movement recordings of patient 1. In figures 4, 5, and 6, rightward eye movements are represented by an upward trace, and leftward eye movements by a downward trace. (A) Saccades, with normal latency, amplitude, and velocity. (B) Smooth pursuit, saccadic bilaterally though mainly rightwards. (C) OKN, asymmetrical, with slower rightward slow phase (horizontal arrows indicate the direction of stimulation, and vertical arrows a change in the direction of stimulation). (D) VOR, normal. (E) VOR suppression, impaired bilaterally, without visible asymmetry. $e=$ eye, $t=$ target.

Table 1 Horizontal saccades latencies and velocity

\begin{tabular}{llllll}
\hline & \multicolumn{2}{l}{ Latency $(m s)$} & & \multicolumn{2}{l}{ Velocity $(\% / s)$} \\
\cline { 2 - 3 } \cline { 5 - 6 } & $R$ & $L$ & & $R$ & $L$ \\
\hline Patient 1 & 300 & 270 & & 402 & 399 \\
Patient 2 & 225 & 240 & & $120^{\star}$ & $144^{\star}$ \\
Patient 3 & 180 & 200 & & 335 & 340 \\
Patient 4 & 228 & 230 & & 355 & 410 \\
$\begin{array}{l}\text { First control } \\
\text { group }\end{array}$ & $237(47)$ & $236(59)$ & & $327(72)$ & $325(72)$ \\
Second control & & & & & \\
group & $197(30)$ & $192(28)$ & & $346(60)$ & $331(58)$ \\
\hline
\end{tabular}

In this and all subsequent tables patients 1,2 , and 4 are compared with the first control group and patient 3 is compared with the second control group. L = left, R = right; ${ }^{\star}$ Outside the normal range (mean (2 SD)) rotating at 0.25 and $0.40 \mathrm{~Hz}$ with a $20^{\circ}$ amplitude on each side of the midline, under two conditions. Under the first condition, the patient was asked to fixate an earth-fixed visual target while being rotated, which tested both the VOR and smooth pursuit. Under the second condition, the visual target was turned off, but the patient was asked to imagine it while being rotated, which tested only the VOR. Ability to suppress the VOR was also studied, the patient being asked to fixate a target rotating with the armchair. Mean gains were calculated for OKN, the VOR, and VOR suppression (ratio of peak eye velocity to peak head velocity).

Two control groups, each of 10 normal subjects, were used, because patient 3 was markedly younger than the other three. The first control group had a mean age of 60 years (range: 51-67 years), and the second a mean age of 35 years (range: 25-44 years). The results of patients 1,2 , and 4 were compared with those of the first control group, and the results of patient 3 with those of the second control group.

\section{Results}

PATIENT 1

Horizontal saccades were accurate and had latency and velocity analogous to those of the first control group (fig 4A and table 1). Smooth pursuit gain was markedly decreased bilaterally, even for a low stimulus velocity (fig 4B and table 2). Furthermore, there was marked asymmetry for each speed (fig 7) with a more severe deficit for rightward smooth pursuit (fig 4B and table 2). Therefore, many catch up saccades were needed to follow the target. OKN slow phase was clearly asymmetrical, with a slower rightward slow phase (fig $4 \mathrm{C})$.

The VOR was symmetrical and qualitatively normal (fig 4D). VOR suppression was impaired bilaterally, as shown by the presence of a vestibular nystagmus, even for slow rotations, without obvious qualitative right-left asymmetry (fig 4E).

Vertical saccades appeared normal, with no dysmetria. Both upward and downward smooth pursuit appeared severely impaired, being almost entirely replaced by catch up saccades.

PATIENT 2

Horizontal visually guided saccades were accurate, with latencies analogous to those of the first control group, but with markedly reduced velocities, bilaterally (fig $5 \mathrm{~A}$ and table 1).

Smooth pursuit was impaired bilaterally (fig 5B and table 2), but predominantly towards the left side, with marked asymmetry for $14.5,22.5$ and $29 \%$ s target velocities (fig 7). This asymmetry disappeared at higher target velocities. The OKN slow phase gain was decreased bilaterally, though more markedly leftwards (fig 5C and table 3).

Under the first condition (the patient fixating an earth-fixed target), the VOR gain was 
Table 2 Horizontal smooth pursuit gain (SD)

\begin{tabular}{|c|c|c|c|c|c|c|c|c|c|c|c|c|}
\hline \multirow{2}{*}{$\begin{array}{l}\text { Target } \\
\text { peak } \\
\text { velocity }\end{array}$} & \multicolumn{2}{|c|}{$\begin{array}{l}\text { Patient } 1 \\
\text { Gain } \\
\text { (SD) }\end{array}$} & \multicolumn{2}{|c|}{$\begin{array}{l}\text { Patient } 2 \\
\text { Gain } \\
\text { (SD) }\end{array}$} & \multicolumn{2}{|c|}{$\begin{array}{l}\text { Patient } 3 \\
\text { Gain } \\
\text { (SD) }\end{array}$} & \multicolumn{2}{|c|}{$\begin{array}{l}\text { Patient } 4 \\
\text { Gain } \\
(S D)\end{array}$} & \multicolumn{2}{|c|}{$\begin{array}{l}\text { First control group } \\
\text { Mean gain } \\
\text { (SD) }\end{array}$} & \multicolumn{2}{|c|}{$\begin{array}{l}\text { Second control group } \\
\text { Mean gain } \\
\text { (SD) }\end{array}$} \\
\hline & $\boldsymbol{R}$ & $L$ & $R$ & $\boldsymbol{L}$ & $\boldsymbol{R}$ & $L$ & $\boldsymbol{R}$ & $L$ & $R$ & $L$ & $R$ & $L$ \\
\hline $14.5 \% / \mathrm{s}$ & & & $\begin{array}{c}0.69^{\star} \\
(0.17\end{array}$ & $\begin{array}{c}0.50^{\star} \\
(0.15)\end{array}$ & $\begin{array}{c}0.71^{\star} \\
(0.12)\end{array}$ & $\begin{array}{c}0.94 \\
(0.10)\end{array}$ & $\begin{array}{c}0.96 \\
(0.05)\end{array}$ & $\begin{array}{c}0.98 \\
(0.05)\end{array}$ & $\begin{array}{c}0.98 \\
(0.06)\end{array}$ & $\begin{array}{c}1.01 \\
(0.07)\end{array}$ & $\begin{array}{c}1.00 \\
0.05)\end{array}$ & $\begin{array}{c}1.00 \\
0.07\end{array}$ \\
\hline $22.5 \% / s$ & $\begin{array}{c}0.13^{\star} \\
(0 \cdot 10)\end{array}$ & $\begin{array}{c}0.28^{\star} \\
(0 \cdot 10)\end{array}$ & $\begin{array}{c}0.62^{\star} \\
(0.12)\end{array}$ & $\begin{array}{c}0.45^{\star} \\
(0.13)\end{array}$ & $\begin{array}{c}0.68^{\star} \\
(0.11)\end{array}$ & $\begin{array}{c}0.83^{\star} \\
(0.15)\end{array}$ & $\begin{array}{c}0.78^{\star} \\
(0.08)\end{array}$ & $\begin{array}{c}0.83^{\star} \\
(0.07)\end{array}$ & $\begin{array}{c}1.02 \\
(0.05)\end{array}$ & $\begin{array}{c}0.99 \\
(0.06)\end{array}$ & $\begin{array}{c}1.05 \\
(0.06)\end{array}$ & $\begin{array}{c}1.06 \\
(0.06)\end{array}$ \\
\hline $29 \% / \mathrm{s}$ & $\begin{array}{c}0.10^{\star} \\
(0.05)\end{array}$ & $\begin{array}{c}0.28^{\star} \\
(0.09)\end{array}$ & $\begin{array}{c}0.62^{\star} \\
(0.16)\end{array}$ & $\begin{array}{c}0.266^{\star} \\
(0.07)\end{array}$ & $\begin{array}{c}0.63^{\star} \\
(0.13)\end{array}$ & $\begin{array}{c}0.75^{\star} \\
(0.13)\end{array}$ & $\begin{array}{c}0.70^{\star} \\
(0.08)\end{array}$ & $\begin{array}{c}0.73^{\star} \\
(0.08)\end{array}$ & $\begin{array}{c}0.94 \\
(0.09)\end{array}$ & $\begin{array}{c}0.93 \\
(0.09)\end{array}$ & $\begin{array}{c}(1.00) \\
(0.00)\end{array}$ & $\begin{array}{c}(0.03) \\
1.03 \\
(0.04)\end{array}$ \\
\hline $45 \% / \mathrm{s}$ & $\begin{array}{c}0.05^{\star} \\
(0.03)\end{array}$ & $\begin{array}{c}0.20^{\star} \\
(0.07)\end{array}$ & $\begin{array}{c}0 \cdot 19^{\star} \\
(0 \cdot 10)\end{array}$ & $\begin{array}{c}0 \cdot 22^{\star} \\
(0 \cdot 13)\end{array}$ & $\begin{array}{c}0.56^{\star} \\
(0 \cdot 11)\end{array}$ & $\begin{array}{c}0.64^{\star} \\
(0 \cdot 11)\end{array}$ & $\begin{array}{c}0.53^{\star} \\
(0.08)\end{array}$ & $\begin{array}{c}0.61 \\
(0.06)\end{array}$ & $\begin{array}{c}0.85 \\
(0.06)\end{array}$ & $\begin{array}{c}0.82 \\
(0.13)\end{array}$ & $\begin{array}{c}0.91 \\
(0.05)\end{array}$ & $\begin{array}{c}0.92 \\
(0.04)\end{array}$ \\
\hline
\end{tabular}

The side of the lesion is denoted in bold. (See also the legend of Table 1.)
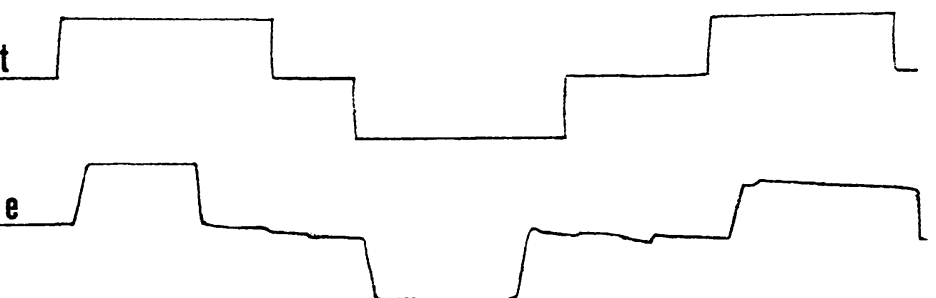

A

B
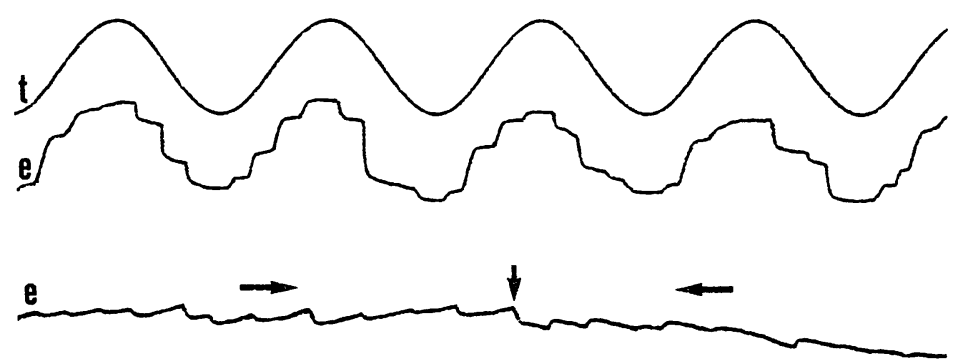

C

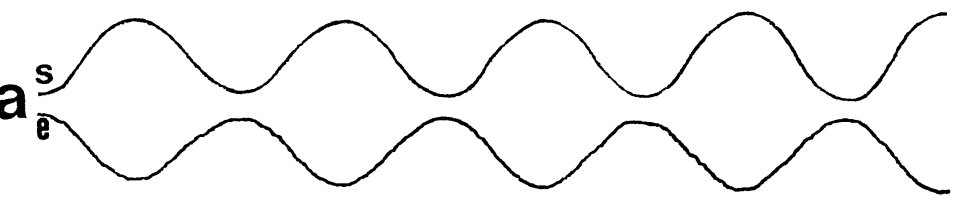

$\mathrm{D}$

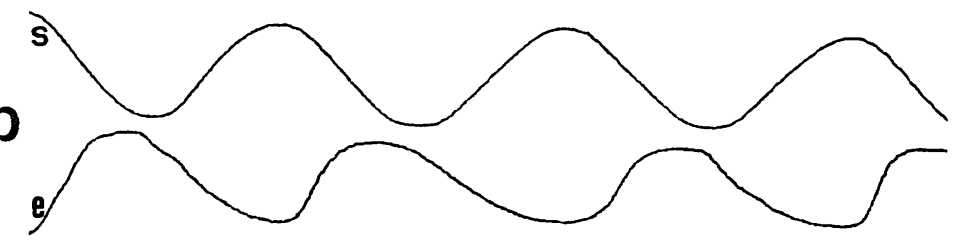

$E$

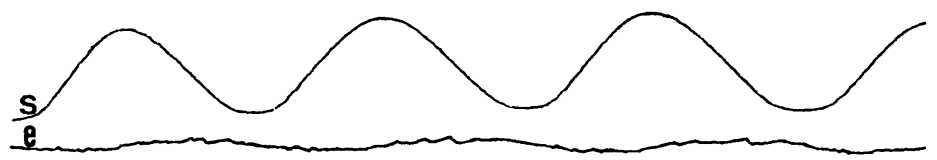

$10^{\circ} \frac{1}{15}$

Figure 5 Horizontal eye movement recordings of patient 2. (A) Saccades, with normal latency and amplitude, but bilateral decreased velocity. (B) Smooth pursuit, saccadic bilaterally, mainly leftwards. (C) OKN, asymmetrical with slower leftward slow phase (horizontal arrows indicate the direction of stimulation, and the vertical arrow a change in the direction of stimulation). (D) VOR (a) under the first condition, with normal gain; (b) under the second condition, asymmetrical with normal leftward gain but increased rightward gain. (E) VOR suppression, impaired bilaterally, though mainly rightwards. $e=$ eye, $s=$ stimulation, $t=$ target. analogous to that of the control group (fig 5D and table 4). Under the second condition, rightward VOR gain increased, but leftward VOR gain was normal, resulting in significant right left asymmetry $(p<0.001$, Student's test) (fig 5D and table 4). VOR suppression gain was impaired bilaterally, though mainly rightwards (fig $5 \mathrm{E}$ and table 4 ). The ratio of leftward gain to rightward gain was approximately 1 for the VOR under the first condition, it was 0.36 for the VOR in the second condition, and 0.35 for VOR suppression.

Vertical saccades $\left(20^{\circ}\right.$ amplitude) had normal latency and accuracy. Their velocity seemed qualitatively normal (about $240 \% \mathrm{~s}$ upwards and $245 \%$ s downwards). Smooth pursuit was almost entirely saccadic both upwards and downwards, and velocity of vertical OKN slow phases was markedly reduced.

\section{PATIENTS 3 AND 4}

Velocity and amplitude of horizontal saccades of patient 3 (fig 6A) and patient 4 were analogous to those of the second and first control groups, respectively (table 1). Smooth pursuit was impaired, mainly at higher target velocities, slightly more ipsilaterally (fig $6 \mathrm{~B}$ and table 2). Asymmetry was slight for targets moving at $14.5 \% \mathrm{~s}, 22.5 \% \mathrm{~s}$, and $45 \%$ for patient 3, and the index of asymmetry was within the normal range for patient 4 (fig 7). Horizontal OKN was similarly impaired, with no (patient 3) (fig 6C and table 3) or slight asymmetry (patient 4) (table 3 ).

In both patients, the VOR was normal under both conditions, and VOR suppression was impaired, with no asymmetry (fig $6 \mathrm{D}$ and $E$, and table 4). Vertical smooth pursuit was qualitatively mildly impaired (that is, slightly saccadic), both upwards and downwards.

\section{Discussion}

All the patients had a limited vascular lesion located in the basis pontis. Two structures, therefore, were damaged, at least partially: the corticospinal tract and the PN. The pontine tegmentum was spared in patients 1 and 3 , and slightly damaged in patients 2 and 4 , on the midline. The contralateral motor deficit existing in all four patients could easily be ascribed to damage to the corticospinal 
Table 3 Horizontal optokinetic nystagmus (OKN) gain

\begin{tabular}{|c|c|c|c|c|c|c|c|c|c|c|}
\hline \multirow{2}{*}{$\begin{array}{l}\text { Stimulus } \\
\text { velocity }\end{array}$} & \multicolumn{2}{|c|}{$\begin{array}{l}\text { Patient } 2 \\
\text { Gain }\end{array}$} & \multicolumn{2}{|c|}{$\begin{array}{l}\text { Patient } 3 \\
\text { Gain }\end{array}$} & \multicolumn{2}{|c|}{$\begin{array}{l}\text { Patient } 4 \\
\text { Gain }\end{array}$} & \multicolumn{2}{|c|}{$\begin{array}{l}\text { First control group } \\
\text { Mean gain (SD) }\end{array}$} & \multicolumn{2}{|c|}{$\begin{array}{l}\text { Second control group } \\
\text { Mean gain }(S D)\end{array}$} \\
\hline & $R$ & $\boldsymbol{L}$ & $\boldsymbol{R}$ & $L$ & $\boldsymbol{R}$ & $L$ & $R$ & $L$ & $R$ & $L$ \\
\hline $\begin{array}{l}10 \% \mathrm{~s} \\
20 \% \mathrm{~s} \\
30 \% \mathrm{~s}\end{array}$ & $\begin{array}{l}0.69 \\
0.40^{\star} \\
0.35^{\star}\end{array}$ & $\begin{array}{l}0 \cdot 46 \\
0 \cdot 15^{\star} \\
0 \cdot 12^{\star}\end{array}$ & $\begin{array}{l}0.40^{\star} \\
0.41^{\star} \\
0.38^{\star}\end{array}$ & $\begin{array}{l}0.53 \\
0.43^{\star} \\
0.39^{\star}\end{array}$ & $\begin{array}{l}0.58 \\
0.50^{\star} \\
0.36^{\star}\end{array}$ & $\begin{array}{l}0.63 \\
0.68 \\
0.68\end{array}$ & $\begin{array}{l}0.77(0.17) \\
0.74(0.11) \\
0.72(0.10)\end{array}$ & $\begin{array}{l}0.78(0.19) \\
0.73(0.14) \\
0.75(0.12)\end{array}$ & $\begin{array}{l}0.78(0.11) \\
0.69(0.07) \\
0.71(0.06)\end{array}$ & $\begin{array}{l}0.77(0.14) \\
0.71(0.11) \\
0.69(0.07)\end{array}$ \\
\hline
\end{tabular}

The stated gain is that of OKN slow phase. The side of the lesion is denoted in bold. (See also the legend of Table 1.)

Table 4 Horizontal VOR and VOR suppression gain

\begin{tabular}{|c|c|c|c|c|c|c|c|c|c|c|}
\hline \multirow{2}{*}{$\begin{array}{l}\text { Stimulus } \\
\text { frequency } \\
(\mathrm{Hz})\end{array}$} & \multicolumn{2}{|c|}{$\begin{array}{l}\text { Patient } 2 \\
\text { Gain }\end{array}$} & \multicolumn{2}{|c|}{$\begin{array}{l}\text { Patient } 3 \\
\text { Gain }\end{array}$} & \multicolumn{2}{|c|}{$\begin{array}{l}\text { Patient } 4 \\
\text { Gain }\end{array}$} & \multicolumn{2}{|c|}{$\begin{array}{l}\text { First control group } \\
\text { Mean gain (SD) }\end{array}$} & \multicolumn{2}{|c|}{$\begin{array}{l}\text { Second control group } \\
\text { Mean gain (SD) }\end{array}$} \\
\hline & $R$ & $\boldsymbol{L}$ & $\boldsymbol{R}$ & $L$ & $\boldsymbol{R}$ & $L$ & $R$ & $L$ & $R$ & $L$ \\
\hline \multicolumn{11}{|c|}{ VOR, first condition } \\
\hline $\begin{array}{l}0.25 \\
0.40\end{array}$ & $\begin{array}{l}0.81 \\
0 \cdot 70\end{array}$ & $\begin{array}{l}0.79 \\
0.88\end{array}$ & $\begin{array}{l}0.91 \\
0.76\end{array}$ & $\begin{array}{l}0.82 \\
0.90\end{array}$ & $\begin{array}{l}0.67 \\
0 \cdot 71\end{array}$ & $\begin{array}{l}0.70 \\
0.80\end{array}$ & $\begin{array}{l}0.81(0.08) \\
0.82(0.18)\end{array}$ & $\begin{array}{l}0.81(0.10) \\
0.84(0.18)\end{array}$ & $\begin{array}{l}0.73(0.10) \\
0.75(0.19)\end{array}$ & $\begin{array}{l}0.71(0.12) \\
0.77(0.19)\end{array}$ \\
\hline \multicolumn{11}{|c|}{ VOR, second condition } \\
\hline $0 \cdot 25$ & $2 \cdot 20^{\star}$ & 0.80 & $0 \cdot 66$ & $0 \cdot 79$ & $0 \cdot 84$ & 0.99 & $0.85(0.12)$ & $0.80(0.12)$ & $0 \cdot 80(0 \cdot 18)$ & $0.78(0.16)$ \\
\hline $0 \cdot 40$ & $1 \cdot 35^{\star}$ & $0 \cdot 85$ & 0.71 & $0 \cdot 72$ & 0.90 & $0 \cdot 85$ & $0.76(0.12)$ & $0.76(0.07)$ & $0.79(0.17)$ & $0.77(0.14)$ \\
\hline \multicolumn{11}{|c|}{ VOR suppression } \\
\hline
\end{tabular}

The side of the lesion is denoted in bold. (See also the legend of Table 1.)

tract. Impairment of smooth pursuit was probably a result of the PN lesions. We will mainly deal with this point, but abnormalities concerning the VOR and horizontal saccades in patient 2 will also be discussed briefly.

\section{SMOOTH PURSUIT AND OPTOKINETIC NYSTAGMUS}

The precise location of the different PN groups is unknown in humans. In the monkey, the PN consist of several contiguous subdivisions, classified using topographical criteria. The classification proposed by Nyby and Jansen, ${ }^{5}$ although obtained using old anatomical techniques, is still used as a reference by modern authors. ${ }^{678}$ They distinguish the median PN, dorsal PN, lateral PN, ventral $\mathrm{PN}$, and peduncular $\mathrm{PN}$, all of which are intermingled with the corticospinal tract. These nuclei extend from the pontomedullary junction to the pontopeduncular junction. ${ }^{6}$ The subdivisions involved in smooth pursuit have recently been investigated. The DLPN have been extensively studied and appear to control smooth pursuit. The DLPN receive afferences from ipsilateral cortical areas involved in smooth pursuit: the middle temporal (MT) and medial superior temporal (MST) areas, ${ }^{6-9}$ and the frontal eye field (FEF). ${ }^{31011}$ The DLPN project to the cerebellar structures involved in smooth pursuitthat is, bilaterally to the oculomotor vermis and the fastigial nucleus, and also bilaterally but mainly contralaterally to the flocculus. ${ }^{12-18}$ Neurons in the DLPN discharge during ipsilateral or contralateral smooth pursuit. ${ }^{19-22}$ Microstimulations applied within the DLPN increase ipsilateral smooth pursuit velocity, but do not elicit slow eye movements if eyes are not already performing smooth pursuit. ${ }^{23}$ It should be noted that the same fact was observed for stimulations of area MST. ${ }^{24}$ Furthermore, it has been reported, in the monkey and in one patient, that a DLPN lesion results in a decrease in smooth pursuit gain, mainly ipsilaterally. ${ }^{45}$ Other PN are also probably involved in smooth pursuit. The lateral PN (LPN) have largely similar connections to those of the DLPN, although they appear to project more heavily to the floccular region than the DLPN. ${ }^{7813}$ A lesion restricted to the LPN in the monkey results in severe impairment of ipsilateral smooth pursuit. ${ }^{25}$ Recent experimental data suggest that the dorsomedian PN (DMPN) are also probably involved in smooth pursuit. ${ }^{26}$ The DMPN receive unilateral afferences from areas MT and MST, and bilateral afferences from the FEF. ${ }^{211}$ They send efferences mainly to the vermis, bilaterally, and also to the contralateral flocculus. ${ }^{21315}$ Cells in these nuclei discharge during smooth pursuit and, in the monkey, a lesion in this area impairs smooth pursuit. ${ }^{2}$ Lastly, the nucleus reticularis tegmenti pontis (NRTP), located at the anterior part of the upper pontine tegmentum and difficult to differentiate anatomically from the nearby DMPN, also appears to be involved in smooth pursuit. ${ }^{2}$ Cells in the rostral NRTP discharge during smooth pursuit, ${ }^{27}$ and stimulation of the NRTP elicits slow eye movements (even if the eyes are not already performing smooth pursuit), ${ }^{28}$ as does stimulation of the FEF. ${ }^{29}$ The NRTP receives afferences from the $\mathrm{FEF}^{30}$ and projects heavily to the flocculus and also to the vermis. ${ }^{1314}$ Lastly, a lesion affecting the NRTP in the monkey results in smooth pursuit impairment. $^{31}$ Therefore, two parallel pathways could control smooth pursuit between the cerebral cortex and the pons: the first could originate in the temporoparietal cortex (areas MT and MST), and project mainly to the DLPN and LPN, whereas the second could originate in the FEF and project mainly to the NRTP and/or the DMPN. The specific roles of these two parallel pathways in smooth pursuit remain, however, to be determined.

Smooth pursuit impairment differed between our four patients. Ipsilateral smooth 


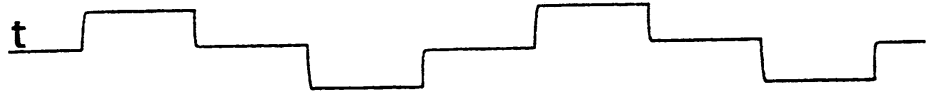

A

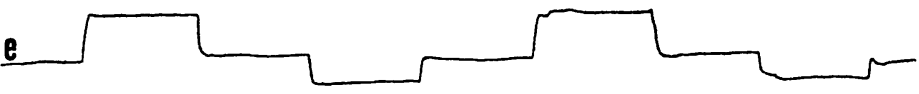

B
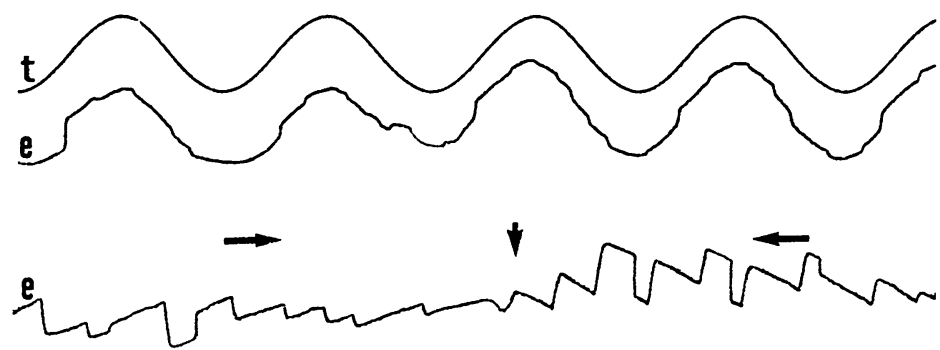

C

a

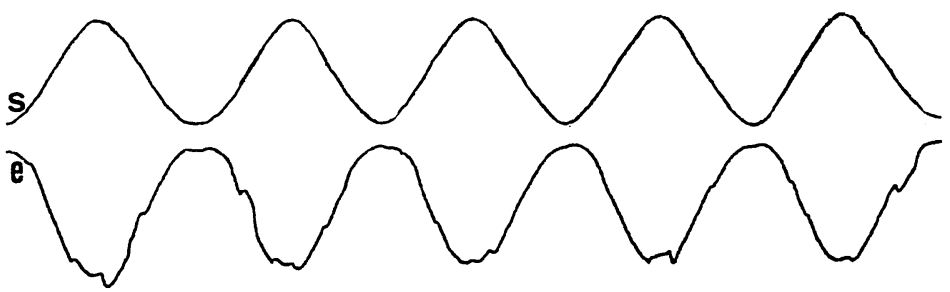

D
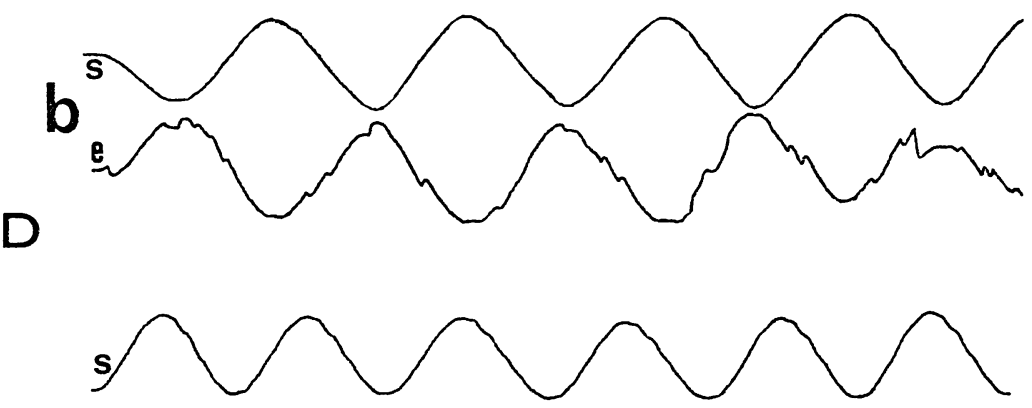

E

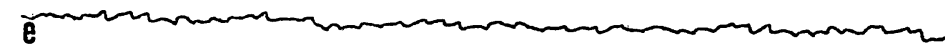

\section{$10^{\circ} \mathrm{L}$}

Figure 6 Horizontal eye movement recordings of patient 3. (A) Saccades, normal. (B) Smooth pursuit, mildly impaired. (C) OKN, mildly impaired horizontal arrows indicate the direction of stimulation, and the vertical arrow a change in the direction of stimulation). (D) VOR (a) under the first condition, normal; (b) under the second condition, normal. (E) VOR suppression, slightly impaired bilaterally. $e=e y e, s=$ stimulation, $t=$ target group and the DMPN group. According to Schmahmann and Pandya, ${ }^{6}$ these two groups are separated by another PN group, the peduncular PN, intermingled with the corticospinal tract. Therefore, the DLPN-LPN group and the DMPN group lie respectively laterally and medially to a virtual anteroposterior line crossing the pons through the central part of the peduncular PN (see fig 2). Thus, it is reasonable to assume that lesions located laterally or medially to this line involve either the DLPN-LPN group or the DMPN group, respectively. According to these anatomical criteria, the DLPN and the LPN were probably extensively damaged in patient 1 (given the large rostrocaudal extent of this lesion), slightly damaged in patient 2 , and intact in patients 3 and 4.

Conversely, the DMPN were partly damaged unilaterally in patients 3 and 4 , and bilaterally in patient 2 , but spared in patient 1. From a comparison of patient 1 and patient 2 , it may be suggested that the extensive impairment of the DLPN and the LPN was responsible for the severe impairment of ipsilateral smooth pursuit in patient 1 . Moreover, a comparison of patients 3 and 4 with patient 2 suggests that the more pronounced impairment of ipsilateral smooth pursuit in patient 2 could be the consequence of the involvement of the DLPN in this patient, the DMPN being partly damaged in all these three patients. Lastly, impairment of horizontal $\mathrm{OKN}$ and vertical smooth pursuit in particular in patients 1 and 2, were consistent with results of experimental DLPN lesions. ${ }^{25}$

Smooth pursuit impairment was less asymmetrical in patient 2 than in patient 1 , partly because of a relatively more marked contralateral smooth pursuit deficit in the former, especially for high target velocities (29 and $45 \%$ ). Patients 3 and 4, with DMPN lesions, had, respectively, slight and no asymmetry in smooth pursuit (fig 7). Slight asymmetry after a DMPN lesion may be due to the medial location of these nuclei. Since the two groups are located on either side of the midline, and their efferences decussate through the basis pontis before projecting to the cerebellum, a single medial lesion may affect both nuclei (as in patient 2) and their efferences. It should also be noted that these nuclei receive bilateral afferences from the FEF. The severe impairment of contralateral smooth pursuit in patients 1 and 2 appears to contradict experimental studies in the monkey, in which DLPN lesions result in only slight or no impairment of contralateral smooth pursuit. ${ }^{25}$ However, these chemically induced lesions, performed by excitotoxic agents, such as ibotenic acid, selectively damage cell soma but spare fibres of passage-that is, efferences from the contralateral pontine nuclei. Therefore, this could explain the difference between the results of experimental and clinical studies.

Our findings in patient 1 are consistent with the results of Thier et al. ${ }^{4}$ These authors reported the first case of selective smooth we are interested-that is, the LPN-DLPN 


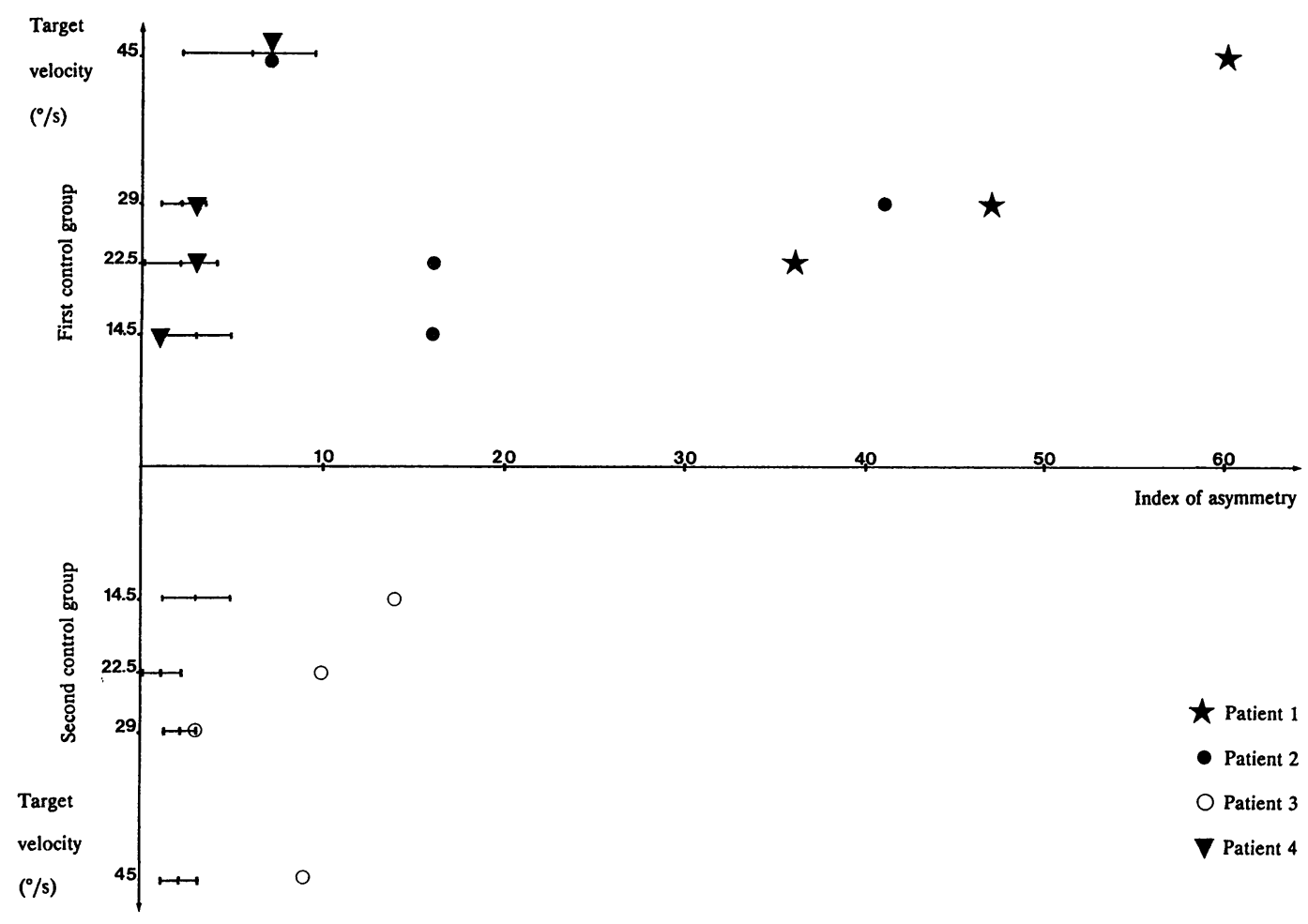

Figure 7 Index of asymmetry of smooth pursuit. Values for each control group are plotted as horizontal bars displaying mean index of asymmetry $\pm S D$. Note that patient 1 , with a DLPN and LPN lesion, had the most marked asymmetry, whereas patients 3 and 4, with DMPN lesions, had slight and no asymmetry, respectively.

pursuit impairment after a PN lesion. According to MRI, the lesion probably involved the LPN-DLPN group. Saccades were normal but smooth pursuit was markedly impaired, bilaterally although mostly ipsilaterally, resulting in a high level of asymmetry. To our knowledge, no previous smooth pursuit study has been reported in a patient with a medially located pontine lesion, considered to involve the DMPN.

Therefore, our results appear to confirm the involvement of the DLPN and LPN in smooth pursuit control, and suggest that the DMPN could be involved in this eye movement as well, though with a minor role. As for the NRTP, its role in smooth pursuit in humans remains to be determined, since this structure was probably spared, either totally or largely, in our four patients.

\section{VESTIBULO-OCULAR REFLEX}

Since the VOR of patient 1 was not tested in complete darkness and was analysed only qualitatively, a slight abnormality of this eye movement cannot be ruled out. VOR suppression was impaired bilaterally in this patient but, unlike smooth pursuit, was symmetrical. A similar discrepancy between smooth pursuit and VOR suppression results was also observed in the patient previously reported. ${ }^{4}$ It has been suggested that VOR suppression does not result only from additional mechanisms between the VOR and smooth pursuit.

In patient 2, rightward gain was about $2 \cdot 20$, whereas leftward VOR gain was normal. Increased VOR gain is uncommon. In humans, bilateral hyperactive VOR has been observed in cerebellar degeneration, ${ }^{32-34}$ and in the monkey, hyperactive VOR has been produced by a reversible lesion affecting the olivofloccular tracts or the inferior olivary nucleus. ${ }^{35}$ The lesion of patient 2 did not appear to involve the flocculus, the olivary nucleus, or the flocculovestibular and olivocerebellar tracts, both passing through the inferior cerebellar peduncle. Therefore, the explanation for such a unilateral hyperactive VOR is unclear. It may be that damage to the afferences of the inferior olivary nucleus was responsible for this abnormality. VOR suppression was likewise impaired bilaterally in patient 2, but predominantly for the rightward hyperactive VOR. However, as the index of asymmetry of the VOR under the second condition and VOR suppression were analogous, it may be suggested that asymmetry observed in VOR suppression was mainly the consequence of VOR asymmetry. In patients 3 and 4 , the VOR tested under both conditions was normal. VOR suppression was mildly impaired bilaterally, without asymmetry.

\section{SACCADES}

Patient 2 had reduced velocity of all horizontal saccades. As no lesions were visible on MRI in the cerebral hemispheres or in the midbrain, it may be suggested that this abnormality was due to the pontine lesion. In the monkey, ${ }^{25}$ as well as in the previously reported case ${ }^{4}$ or in our patient 1, DLPN or LPN lesions did not result in a decrease in saccade velocity. Moreover, a lesion in the DMPN area does not seem to reduce saccade velocity, as shown by patients 3 and 4 . 
Therefore, it may be assumed that this saccade abnormality was due to the small median tegmental extent of the lesion, probably involving the pontine paramedian reticular formation (PPRF). The lesion of patient 4 impinged also slightly in the pontine tegmentum, but to a lesser extent than that of patient 2 . Therefore, the PPRF was probably spared in this patient, with saccades of normal velocity.

This work was supported by the Direction de la Recherche Clinique (N 91.2215).

1 Brodal P. The pontocerebellar projection in the rhesus monkey: an experimental study with retrograde axonal transport of horseradish peroxidase. Neuroscience 1979; 4:193-208.

2 Keller EL, Heinen SJ. Generation of smooth-pursuit eye movements: neuronal mechanisms and pathways. Neurosci Res 1991;11:79-107.

3 Leichnetz GR. Inferior frontal eye field projections to pursuit related dorsolateral pontine nucleus and middle temporal area (MT) in the monkey. Vis Neurosci 1989;3:171-80.

4 Thier P, Bachor A, Faiss J, Dichgans J, Koenig E. Selective impairment of smooth pursuit eye movements Selective impairment of smooth pursuit eye movements
due to an ischemic lesion of the basal pons. Ann Neurol due to an ischemic
$1991 ; 29: 443-8$.

5 Nyby O, Jansen J. An experimental investigation of the corticopontine projection in Macaca mulatta. Norske Videnskaps Akad Oslo Nat 1951;3:1-47.

6 Schmahmann JD, Pandya DN. Projections to the basis pontis from the superior temporal sulcus and superior temporal region in the rhesus monkey. $f$ Comp Neurol 1991;289:224-48.

7 Glickstein M, May J, Mercier BE. Corticopontine projection in the macaque: the distribution of labeled cortical cells after large injections of horseradish peroxidase in the pontine nuclei. $\mathcal{F}$ Comp Neurol 1985;253:343-59.

8 May JG, Andersen RA. Different patterns of corticopontine projections from separate cortical fields within the inferior parietal lobule and dorsal prelunate gyrus of the inferior parietal lobule and dorsal prelunate
macaque. Exp Brain Res 1986;63:265-78.

macaque. Exp Brain Res 1986;63:265-78.
9 Ungerleider LG, Desimone R, Galkin TW, Mishkin M. Ungerleider LG, Desimone R, Galkin TW, Mishkin $M$.
Subcortical projections of area MT in the macaque. $\mathcal{f}$ Comp Neurol 1984;223:368-86.

10 Huerta MF, Kaas JH. Supplementary eye field as defined by intracortical microstimulation in macaques. $f$ Comp Neurol 1990;293:299-330.

11 Stanton GB, Goldberg ME, Bruce CJ. Frontal eye field efferents in the macaque monkey. II. Topology of terminal fields in midbrain and pons. $f$ Comp Neurol 1988;271:493-506.

12 Hoddevik GH, Brodal A, Kawamura K, Hashikawa T. The pontine projection to the cerebellar vermal visual area studied by means of the retrograde axonal transport of horseradish peroxidase. Brain Res 1977;123:209-27.

13 Langer T, Fuchs AF, Scudder CA, Chubb MC. Afferents to the flocculus of the cerebellum in the rhesus macaque to the flocculus of the cerebellum in the rhesus macaque
as revealed by retrograde transport of horseradish peroxas revealed by retrograde transport of
idase. $\mathcal{F}$ Comp Neurol 1985;235:1-25.

14 Noda H, Sugita S, Ikeda Y. Afferent and efferent connections of the oculomotor region of the fastigial nucleus in the macaque monkey. F Comp Neurol 1990;302:330-48.

15 Yamada J, Noda $H$. Afferent and efferent connections of the oculomotor cerebellar vermis in the macaque monkey. $₹$ Comp Neurol 1987;265:224-41.

16 Suzuki DA, Keller EL. The role of the posterior vermis of monkey cerebellum in smooth-pursuit eye movement control. I. Eye and head movement-related activity. control. I. Eye and head
$\mathcal{J}$ Neurophysiol $1988 ; 59: 1-18$

17 Zee DS, Yamazaki A, Butler PH, Gucer G. Effects of ablation of flocculus and paraflocculus on eye movement in primate. 7 Neurophysiol 1981;46:878-99.

18 Büttner U, Fuchs AF, Markert-Schwab G, Buckmaster P. Fastigial nucleus activity in the alert monkey during slow eye and head movements. $\mathcal{F}$ Neurophysiol 1991; 65:1360-71.

19 Mustari MJ, Fuchs AF, Wallman J. Response properties of dorsolateral pontine units during smooth pursuit in the rhesus macaque. $\mathcal{F}$ Neurophysiol 1988;60:664-86.

20 Suzuki DA, Keller EL. Visual signals in the dorsolateral pontine nucleus of the alert monkey: their relationship to smooth-pursuit eye movements. Exp Brain Res to smooth-pursuit

21 Suzuki DA, May JG, Keller EL, Yee RD. Visual motion response properties of neurons in dorsolateral pontine nucleus of alert monkey. $\mathcal{F}$ Neurophysiol 1990;63:37-59.

22 Thier P, Koehler W, Buettner UW. Neuronal activity in the dorsolateral pontine nucleus of the alert monkey modulated by visual stimuli and eye movements. Exp Brain Res 1988;70:496-512.

23 May JG, Keller EL, Crandall WF. Changes in eye velocity during smooth pursuit tracking induced by microstimulation in the dorsolateral pontine nucleus of the macaque. Soc Neurosci Abstr 1985;11:79.

24 Komatsu H, Wurtz RH. Modulation of pursuit eye movements by stimulation of cortical areas MT and MST. $\mathcal{F}$ ments by stimulation of cortic

25 May JG, Keller EL, Suzuki DA. Smooth pursuit eye movement deficits with chemical lesion in the dorsolat eral pontine nucleus of the monkey. $\mathcal{F}$ Neurophysio 1988;59:952-77.

26 Keller EL and Crandall WF. Neuronal responses to optokinetic stimuli in pontine nuclei of behaving monkey. $\mathcal{F}$ Neurophysiol 1983;49:169-87.

27 Suzuki DA, Yamada T, Betelak KF, Yee RD. Smoothpursuit eye movement related activity in monkey nucleus reticularis tegmenti pontis. Soc Neurosci Abst 1991;17:459.

28 Yamada T, Suzuki DA, Betelak KF, Yee RD. Initial eye position dependence of eye movements evoked by microstimulation of the monkey nucleus reticularis microstimulation of the monkey nucleus re
tegmenti pontis. Soc Neurosci Abstr 1991;17:459.

29 Bruce CJ, Goldberg ME. Primate frontal eye fields: I Physiological and anatomical correlates of electrically Physiological and anatomical correlates of electrically

30 Stanton GB, Goldberg ME, Bruce CJ. Frontal eye field efferents in the macaque monkey: II. Topography of terminal fields in midbrain and pons. $\mathcal{F}$ Neurophysiol 1988;271:493-506.

31 Suzuki DA, Yee RD, Betelak K. Deficits in smoothpursuit eye movements following lidocaine injection in monkey nucleus reticularis tegmenti pontis. Soc Neurosci Abstr 1990;16:903.

32 Baloh RW, Konrad HR, Honrubia V. Vestibulo-ocular function in patients with cerebellar atrophy. Neurology 1975;25:160-8.

33 Thurston SE, Leigh RJ, Abel LA, Dell'Osso LF. Hyperactive vestibulo-ocular reflex in cerebellar degeneration: pathogenesis and treatment. Neurology 1987; eration:

34 Zee DS, Yee RD, Cogan DG, Robinson DA, Engel WK. Ocular motor abnormalities in hereditary cerebellar ataxia. Brain 1977;99:207-34.

35 Demer JL, Robinson DA. Effects of reversible lesions and stimulation of olivocerebellar system on vestibuloocular reflex plasticity. $\mathcal{F}$ Neurophysiol 1982;47:1084-107. 